\title{
JOGOS DE GÊNERO EM PEQUIM 2008: REPRESENTAÇÕES DE FEMINILIDADES E MASCULINIDADES (RE)PRODUZIDAS PELO SITE TERRA'
}

\section{MS. JOHANNA COELHO VON MÜHLEN}

Doutoranda do Programa de Pós-Graduação em Ciências do Movimento Humano da Escola de Educação Física da Universidade Federal do Rio Grande do Sul (PPGCMH - ESEF/UFRGS) (Porto Alegre - Rio Grande do Sul - Brasil)

E-mail: johanna.coelho@hotmail.com

DRA. SILVANA VILODRE GOELLNER

Professora Associada da Escola de Educação Física da Universidade Federal do Rio Grande do Sul

(ESEF/UFRGS) (Porto Alegre - Rio Grande do Sul - Brasil)

Pesquisadora CNPq

E-mail: vilodre@gmail.com

\begin{abstract}
RESUMO
Fundamentado na perspectiva pós-estruturalista, mais especificamente nos Estudos de Gênero e nos Estudos Culturais, esse artigo tem como objetivo analisar as representações de gênero produzidas e reproduzidas pelo site Terra sobre os atletas participantes dos Jogos Olímpicos de Pequim. Para tanto foram coletados todos os textos e imagens publicados na seção "Últimas Notícias" e "Fotos" durante os dezessete dias de competição. O material empírico constou de reportagens e imagens que foram metodologicamente tratados pela análise de discurso de inspiração foucaultiana. Dessa análise foi possível perceber que o site Terra exibiu diferentes masculinidades e feminilidades, possibilitando a emergência de um "jogo de gênero", no qual diferentes modos de ser atleta foram representados.
\end{abstract}

PALAVRAS-CHAVE: Estudos Culturais; mídia; gênero; Jogos Olímpicos.

I. Agência de fomento: CNPq. 
Em época de comemorações acerca da conquista do Brasil em sediar, pela primeira vez na América Latina, uma edição dos Jogos Olímpicos, imagens espetacularizadas de diferentes atletas circulam em vários artefatos midiáticos, capturando nosso olhar e, de certo modo, nos subjetivando a participar como espectadores e, ao mesmo tempo, partícipes do "espírito olímpico" que paira no ar. Considerados como protagonistas desse espetáculo, os/as atletas são percebidos como um símbolo de determinação, sucesso e superação. Sua frequente exposição exerce, de certo modo, uma pedagogia que ensina valores, formas de ser e de se comportar como atleta, assim como dá visibilidade a alguns marcadores sociais como, por exemplo, classe, raça/etnia, gênero, nacionalidade e religião.

Fundamentado nos Estudos Culturais (EC) e nos Estudos de Gênero a partir da perspectiva pós-estruturalista (SCOTT, I995; LOURO, 2004), este texto analisa as representações ${ }^{2}$ de masculinidades e feminilidades de atletas que participaram dos Jogos Olímpicos de Pequim que circularam em um artefato cultural específico: o site Terra.

A escolha do termo artefato cultural está baseada em autores que assumem a mídia como parte da cultura, entendendo-a como uma pedagogia cultural (SILVA, 2007; FISCHER, 2003). Ao utilizar a expressão pedagogia cultural, ancorado nos EC, estamos autorizados a estender nosso olhar para além da escola e entrever que não é somente nesse espaço que os corpos são educados, moldados, governados. Nesse sentido, "existe pedagogia em qualquer lugar onde o conhecimento é produzido, em qualquer lugar em que exista a possibilidade de traduzir experiências e construir verdades" (GIROUX; MACLAREN, 1995, p. 144)

A opção pelo site Terra se deu em função da possibilidade que o webjornalis$\mathrm{mo}^{3}$ tem de noticiar os acontecimentos em tempo real, promovendo a atualização ininterrupta de notícias. No caso específico dessa edição dos Jogos, em função do fuso-horário ${ }^{4}$ em relação à China, grande parte das competições foram realizadas durante a madrugada no Brasil, o que fez com que a consulta nas reportagens publicadas na internet tivesse grande procura. Essa demanda já estava prevista pelo

2. Consoante a perspectiva teórica desta pesquisa, por representação entende-se "a produção de significados através da linguagem" (HALL, 1997, p. 16). Não é, portanto, um reflexo daquilo que vemos. É uma construção que envolve as práticas de significação e os sistemas simbólicos através dos quais os significados são construídos. Envolve relações de poder: "poder de nomear, de descrever, de classificar, de diferenciar..." (MEYER, 1998, p. 2I).

3. Sobre o uso do termo webjornalismo ler Marcos Palacios (200I).

4. O fuso-horário do Brasil em relação à China é de aproximadamente 12 horas a mais. 
próprio Comitê Olímpico Internacional (COI), quando advertiu que essa seria a edição dos Jogos cuja cobertura promoveria a maior assistência em I I 2 anos de história da competição, fundamentalmente, em função da utilização da internet como um modo de divulgar as notícias (JOGOS DE PEQUIM TEM RECORDE DE AUDIÊNCIA, INTERNET É DESTAQUE, 2008).

A opção pelo recorte analítico de gênero ancora-se na percepção de que o esporte, como qualquer outra prática cultural, é generificado e generificador. Ou seja, seu acontecer está perpassado pela (re)produção de masculinidades e feminilidades, e estes marcadores identitários não são neutros nem universais. Ao contrário: constroem-se cotidianamente considerando as representações culturais a eles associados. São também produzidos por meio de processos de aprendizagem que se fazem presentes nos discursos médicos, familiares, religiosos, pedagógicos, jurídicos e, ainda, naqueles que circulam em diferentes outros meios de comunicação.

Para a vertente pós-estruturalista, o gênero é observado como algo que integra a identidade do sujeito, que faz parte da pessoa e a constitui. Decorre dessa representação uma importante diferenciação com relação a outras abordagens analíticas como, por exemplo, aquelas que recorrem a conceitos como os de estereótipo e/ou papéis sexuais. Papéis e estereótipos revelam-se como estruturas fixas baseadas em padrões ou regras estabelecidas por cada sociedade, nas quais os sujeitos aprendem a ser homens e mulheres adaptando-se ou aprendendo a comportar-se de acordo com esses papéis. Nesse caso, ficariam sem exame não apenas as múltiplas formas que podem assumir as masculinidades e feminilidades, como também as complexas redes de poder que (através das instituições, dos discursos, dos códigos, das práticas e dos símbolos...) constituem hierarquias entre os gêneros (LOURO, 1997).

$\mathrm{Na}$ vertente teórica aqui assumida, masculinidade e feminilidade se definem reciprocamente, visto não existir nenhuma essência a priori determinada para uma e outra identidade. Essas identidades, ao contrário, são produzidas na cultura através de inúmeras práticas sociais, dentre elas, o esporte.

Com relação à mídia, partimos do pressuposto que, tanto quanto o esporte, traduz-se em instância cultural que coloca em circulação diferentes representações de masculinidades e feminilidades, bem como promove diferenciações nos modos pelos quais as notícias exibem e conferem visibilidade a atletas homens e mulheres em eventos de pequeno, médio ou grande porte.

\section{O SITE TERRA E AS REPRESENTAÇÕES DE GÊNERO}

Durante o período de realização dos Jogos (08 e 24 de agosto de 2008), o site Terra produziu uma profusão de informações no formato de reportagens, 
notícias, vídeos, entrevistas, entre outras. Foram catalogadas, aproximadamente, 800 reportagens e 8000 fotografias. Para identificar as representações de gênero veiculadas nestas imagens e reportagens, recorremos à análise de discurso de inspiração foucaultiana ${ }^{5}$, uma vez que possibilita compreender a produção social de sentidos através da linguagem. Justificamos tal escolha pela importância da aproximação entre estudos da mídia e análise de discurso, a fim de compreender os movimentos discursivos de produção de identidades (GREGOLIN, 2007), neste caso específico, as identidades de gênero.

Lembremos com Foucault (2005) que, embora os discursos sejam constituídos de signos, eles fazem mais que utilizar esses signos para designar coisas. É esse "mais" que é preciso fazer aparecer, e que é preciso descrever. Esse algo a mais que o autor menciona sugere que, além de designar coisas, objetos, pessoas, mundo, os discursos também criam coisas, produzem novos objetos; enfim, formam "sistematicamente os objetos de que falam" (SILVA, 200 I, p. 43).

Se todos os sujeitos estão imersos num campo discursivo, como adverte Foucault (2005), sua produção está imersa em relações de poder. Portanto, se por um lado os discursos são produzidos em meio a relações de poder que instituem o que eles dizem e como dizem, por outro, envolvem os efeitos de poder que são colocados em funcionamento nos discursos e através deles. De outro modo, podemos entender que essas relações envolvem enunciados, falas, visibilidades, textos, imagens, sons, que constituem práticas sociais que estão permanentemente engendradas às relações de poder, as quais produzem, reproduzem e atualizam essas relações.

Para Foucault (2004), o poder, antes de ser algo que se possua, é algo que se exerce constantemente, pois em qualquer sociedade existem relações de poder múltiplas que atravessam, caracterizam e constituem as distintas instâncias sociais. O poder está em toda parte, visto que advém de todos os lugares e, considerando que não há sujeito fora do poder, pode-se dizer que alguns sujeitos são melhor posicionados do que outros, alguns se reconhecem ao serem representados em

5. Existem diferentes modos de operar com a análise de discurso decorrentes das distintas escolas que elaboraram suas referências epistemológicas. Segundo Orlandi (2003), inicialmente destacaram-se duas grandes correntes no campo da AD: a americana, que pende para um lado mais pragmático e que se caracteriza pelo estudo da linguagem em uso, ou seja, da relação dos signos com seus interpretes; e a francesa, que opera mais especificamente com a materialidade da língua buscando perscrutar os efeitos semânticos imersos na relação língua/sujeito/história. Nessa última vertente destacam-se as perspectivas formuladas por Michel Pêcheux e Michel Foucault. Para maiores informações entre as convergências e divergências entre esses dois autores, ler: Orlandi (2003); Gregolin (2007). 
certos discursos, enquanto que outros não o são ou são em parte. Numa pluralidade de discursos, importa observar quem pode dizer o que, ou seja, que sujeitos são autorizados a falar e sobre o que falam. Ou ainda, que sujeitos são visibilizados e como o são.

Pensando especificamente no siteTerra, importa perceber quem são os sujeitos visibilizados, o que se diz sobre eles/elas, e como se diz. A análise de discurso de inspiração foucaultiana opera aqui na tentativa de identificar as dizibilidades e visibilidades que circulam em dada materialidade discursiva, neste caso, nas reportagens e imagens veiculadas durante a realização dos Jogos de Pequim. Nesse sentido, nos apropriamos dessa ferramenta metodológica objetivando descortinar os textos e imagens produzidos pelo site Terra acerca das representações de gênero. Buscamos, então, olhar para a exterioridade das palavras, pois é lá que está o discurso que, grosso modo, constrói uma vontade de verdade. Para Foucault (2005, p. I 17), analisar o discurso é fazer com que "desapareçam e reapareçam as contradições, é mostrar o jogo que nele elas desempenham, é manifestar como ele pode exprimi-las, dar-lhes corpo, ou emprestar-lhes uma fugidia aparência".

Para compreender como determinados discursos ganharam certos sentidos no site Terra, no que respeita as questões relacionadas com masculinidades e feminilidades, estruturamos o trabalho analítico seguindo três etapas: a definição do que analisar, a seleção do material a ser analisado e a análise propriamente dita (IÑIGUEZ, 2004). Nesse sentido, elegemos as representações de gênero como o lócus de nossa problematização. Assim, mergulhamos no vasto material empírico coletado, buscando extrair aqueles textos e imagens que fossem relevantes para tal intento. Nesse sentido, elegemos dois espaços que o site criou para divulgar informações relacionadas aos atletas e suas performances: as seções "Últimas Notícias" e "Fotos". O primeiro era destinado às reportagens sobre a competição sendo, em sua maioria, curtas, com no máximo uma página que continha uma narrativa extremamente técnica. Nele os internautas podiam se informar sobre os resultados das provas e outras notícias relacionadas a número de competidores, medalhistas, entre demais aspectos. Nesse link eram disponibilizadas, em média, 60 reportagens por dia.

Na seção "Fotos", foram publicadas, diariamente, entre 300 e 500 fotografias, cuja exibição incluía um título e um subtítulo (por conjunto de imagens), sendo que cada imagem possuía, ainda, uma legenda específica, salvo alguns poucos casos, nos quais a imagem não estava acompanhada de legenda ${ }^{6}$.

6. Para visualizar melhor a distribuição das imagens, acesse: http://esportes.terra.com.br/pequim2008/ultimas/galerias/0,,El I0378,00.html. Acesso em: I 2 set de 20 I 0. 
Feita essa seleção, operacionalizamos a análise fazendo, primeiramente, uma catalogação das reportagens e fotografias selecionadas em planilha Excel, cujo uso facilitava a visualização da totalidade dos documentos selecionados. A partir daí, identificamos as temáticas mais recorrentes e as agrupamos, objetivando conferir consistência argumentativa, a partir da articulação entre os fundamentos teóricos e o material empírico, considerando, sobretudo, a noção de discurso como o "espaço de articulação de uma rede de relações de poder-saber que delimita e ordena o que pode ser dito em um determinado momento histórico e a noção de sujeito como uma posição a ser ocupada no interior de uma dada formação discursiva" (GOELLNER et al., 20 I0).

No que tange as imagens, nos apropriamos da perspectiva analítica proposta por Rose (2007) que, inspirada na análise de discurso de foucaultina, envolve três instâncias: os espaços de produção da imagem, o espaço da imagem em si e os espaços em que a imagem é visualizada pelos diversos públicos. Tal indicação implica considerar que a visualidade (como vemos, como somos capazes de ver e o que podemos ver) não é natural nem universal, pois os marcadores sociais - como, por exemplo, gênero, classe, geração, etnia, religião - conformam nosso modo de ver.

Com relação às representações de gênero, analisamos os modos como Terra se referiu às masculinidades e às feminilidades, buscando, ainda, evidenciar que tais marcadores identitários não são unívocos. Nesse sentido, olhamos para os/as atletas buscando localizar em seus corpos e comportamentos, modos de ser masculino e feminino que permitam pensar sobre as fronteiras culturalmente relacionadas a eles. Em outras palavras, evitamos compreendê-los a partir de determinados estereótipos que fixam e engessam essas representações, exatamente, porque a ancoragem teórica adotada indica que os modos através dos quais os sujeitos aparentam e vivem suas masculinidades e feminilidades são diversos, instáveis e plurais (GOELLNER, 2007; LOURO, 2004; MEYER, 2004).

Considerando essas premissas, analisamos o material empírico coletado e percebemos que alguns temas eram recorrentes no site, os quais se tornaram as unidades de significado sobre as quais debruçamos nossas análises. Estas foram agrupadas por aproximação temática, conformando duas categorias de análise: "Superatletas: masculinidades e feminilidades em exibição", e "Musas e musos: a beleza rouba a cena", as quais desenvolvemos a seguir.

\section{SUPER ATLETAS: MASCULINIDADES E FEMINILIDADES EM EXIBIÇÃO}

Durante a realização dos Jogos, o site Terra fez circular, em grande número, matérias e imagens destacando os/as atletas e suas performances, nas quais foi possível identificar uma grande valorização das imagens dos/as atletas olímpicos/as 
como heróis/heroínas, visto que aos seus feitos foram agregados valores positivados, e exibidos como sinônimos de superação, vitória, desafio, coragem, determinação, entre outros.

Grande parte das reportagens apresentava uma narrativa sucinta e descritiva, cujo enfoque estava localizado nos resultados e aspectos técnicos da performance. As imagens, em sua maioria, exibiam atletas realizando gestos esportivos próprios às modalidades que competiam, ou ainda, no momento de comemoração por seus resultados, demonstrando suas emoções ao obter um lugar no pódio.

Em uma primeira análise, percebemos uma forma padronizada e generalizada de representar o/a atleta olímpico/a, na qual questões relacionadas ao gênero não figuraram como marcadores principais. No entanto, ao deslocarmos mais atenção ao modo como essas palavras e imagens circularam no site, considerando sua posição e frequência, percebemos que, para além da construção de imagens de superatletas, representações de masculinidades e feminilidades foram tomadas para conferir maior ou menor visibilidade a determinados competidores/as.

Uma representação de feminilidade que circulou no material analisado apontava para a identificação da maternidade como algo essencial à "natureza feminina", indicando o quanto essa função ocupa uma posição central no processo de constituição do sujeito contemporâneo, nos modos de ser homem e mulher, inclusive nos de ser pai, mãe e gestante. $\bigcirc$ tema da maternidade como algo inerente à identidade da mulher, inclusive a atleta, é recorrente em vários estudos que colocam em diálogo as questões de gênero e as práticas corporais no Brasil (MOURÃO, 2000; GOELLNER, 2003) e em outros países como, por exemplo, na Argentina (SCHARAGRODSY, 2006), Alemanha (PFISTER, 200 I) Estados Unidos (BIRRELL; THEBERGE, 1994), Reino Unido (WHITE, 2003), França (LIOTARD; TERRET, 2005), Espanha (AJA, 2002) e Portugal (CRUZ et al., 2006).

Em uma reportagem sobre o vôlei de praia, lemos: "Desde que conquistaram o ouro nos Jogos de Atenas 2004, as duas jogadoras dos EUA se casaram e, apesar de quererem dar o próximo passo no que se trata de família, estão divididas sobre o quanto poderiam jogar como mães"7. Aqui se percebe um certo temor de que a carreira profissional de atletas mulheres possa apresentar impeditivos para que sejam boas mães. Talvez, por essa razão, nessa edição dos Jogos, as mães-atletas ganharam o título de "supermães", como pode ser percebido no excerto a seguir:

Mães do mundo, levantem-se e aplaudam a maratonista britânica Paula Radcliffe e a nadadora norte-americana Dara Torres, que competiram na Olimpíada neste domingo.

7. Disponível em http://esportes.terra.com.br/pequim2008/interna/0,,OI3080565-El I 0378,00.html Acesso em 08 de set.2008. 
Radcliffe, de 34 anos, detentora do recorde mundial, e Torres, a mais velha nadadora norte-americana aos $4 \mathrm{I}$ anos, estão entre o número crescente de mães atletas competindo em Pequim, provando que bebês não significam o fim para a elite esportiva. Talvez até ajude ser mãe. [...] Um estudo com mães da elite do esporte feito pela Universidade Massey, na Nova Zelândia, apresentado em uma conferência de gerenciamento esportivo no ano passado, descobriu que o número de mães envolvidas em esporte de alto nível aumentou na ultima década, mas não ofereceu cifras. CORPO OU MENTE? Ainda não há consenso se as mudanças físicas durante a gravidez podem reforçar a capacidade aeróbica e melhorar o desempenho feminino depois de dar à luz ou se o impacto mental do parto é um fator de melhoria do desempenho pós-parto. (SUPERMÃES DEIXAM SUA MARCA EM PEQUIM, 2008).

Mesmo apontando o esporte como uma possibilidade de fortalecer o corpo da mulher, este artefato cultural parece evidenciar discursos naturalizados sobre a maternidade, tendo como foco questões relacionadas aos aspectos biológicos do corpo e sua influência sobre o desempenho esportivo. Se, em outros tempos, a natureza do corpo feminino era a responsável pelo não aconselhamento de práticas esportivas consideradas pesadas ou violentas, hoje, recorre-se à mesma idéia de uma dada natureza para provar o quanto ser mãe pode auxiliar no rendimento atlético das mulheres. Esse deslocamento faz ver que não são os aspectos anatômicos do corpo feminino aqueles que tencionam a representação, mas, sobretudo, questões culturais e ele relacionadas e que fazem ver que, apesar do treinamento necessário para a construção de uma mulher como atleta, sua função materna não é suprimida ou anulada, como poderia se pensar outrora.

Outra questão a ser analisada reside no significado atribuído a ser mãe ou ser pai para as/os atletas olímpicas/os. Durante os Jogos de Pequim, uma mãe em especial e sua filha tiveram grande espaço na mídia brasileira: Maurren Maggi - a primeira mulher a conquistar uma medalha olímpica individual para esporte nacional - e sua filha Sofia. Em várias reportagens veiculadas no site relacionadas à atleta, quem ganha destaque é Sofia, representada como uma das principais responsáveis pela conquista da mãe. Vejamos:

"Minha filha queria prata, mas o ouro é muito melhor", destacou a saltadora, que melhorou as expectativas iniciais da filha. A filha é de certa forma um dos motivos para a recuperação da atleta. Após ficar dois anos suspensa por ser flagrada positivamente no antidoping, Maurren planejava encerrar a carreira para cuidar da família que planejava iniciar com Antonio Pizzonia, ex-piloto de fórmula I e seu ex-marido. [...] "A Sofia disse que me ama muito, mas brigou comigo e disse que queria a medalha de prata. Eu falei 'filha, deixa a de ouro'! Ela disse 'te amo muito' e eu 'te amo mais'! Filha obrigada por existir na minha vida", explicou Maurren aos prantos. ("MINHA FILHA QUERIA PRATA”, BRINCA MAURREN, 2008) 
O espaço e a ênfase dada à mãe e filha, dizem o quanto é necessário reforçar o amor que uma mãe sente por seu filho e, mais que isso, o quanto é possível ser uma "boa mãe" mesmo sendo atleta, pois além de serem capazes de gerar filhos, são capazes de criá-los dentro das expectativas que uma boa maternagem requer.

Segundo Moreira e Nardi (2008), existe uma espécie de "norma" da maternidade, que possibilita a edificação de que existe uma unidade materna, configurando um único modo de ser mãe, considerado como o mais adequado e legítimo. Pensando especificamente nas reportagens e imagens veiculadas pelo site, identificamos que o fato de uma atleta ser mãe a colocava em um local de destaque. Chama atenção o fato de somente terem sido fotografadas mães com suas/seus filhas/os, e nunca pais. Uma delas, publicada sob a legenda "Americanas levaram até os filhos para o pódio do ouro", parece exemplar dessa diferenciação:

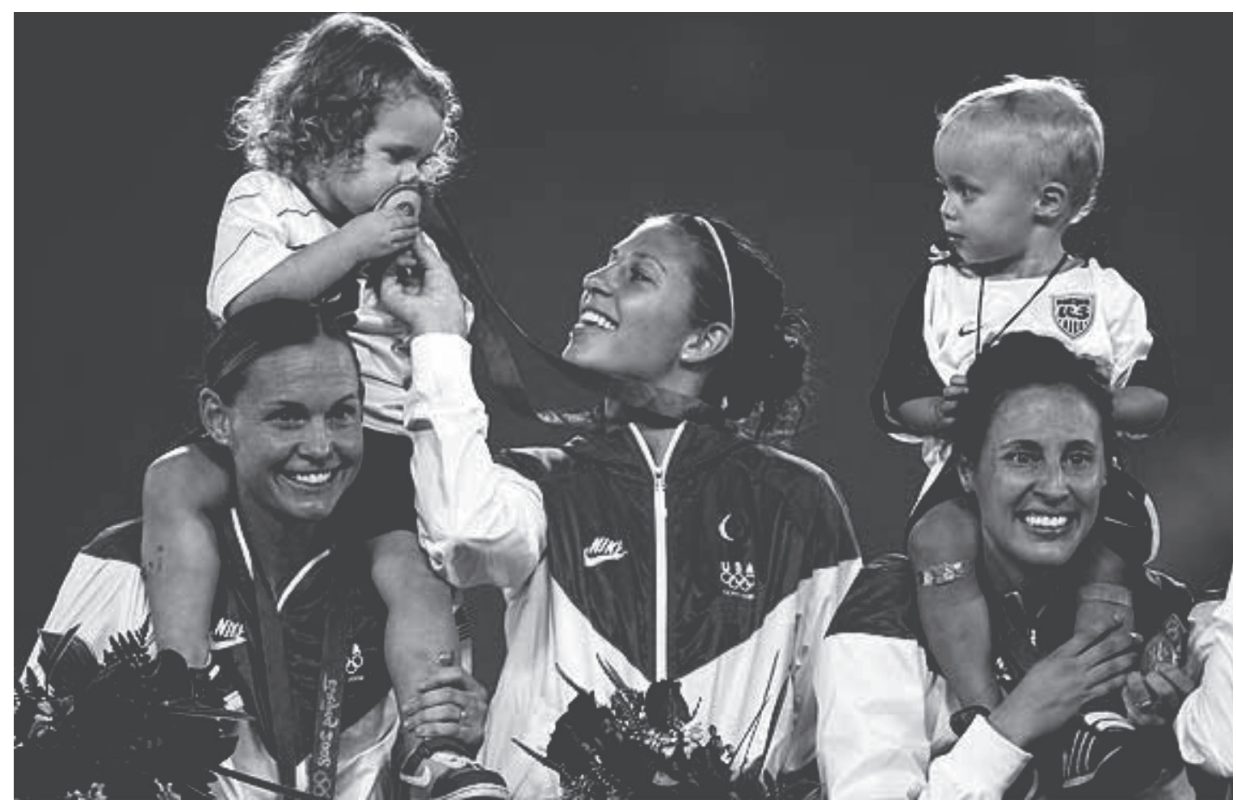

Figura I. Brasil deixou ouro com EUA na final (24 de Agosto de 2008).

Fonte: http://esportes.terra.com.br/pequim2008/galerias/0,,Ol72730-El I0378,00.html . Acesso em: I2 out. 2008.

A imagem retrata as jogadoras de futebol feminino americanas, com as respectivas medalhas de ouro no peito, e seus filhos/filhas participando da conquista olímpica das mães. Longe de ser neutra, essa imagem mostra o quanto é importante representar, ao mesmo tempo, a mesma pessoa como mãe e atleta. Permite pensar, ainda, o quanto atletas de futebol, modalidade tida como de domínio masculino, podem ser "femininas", nesse caso, sendo mães. Essa recorrente forma de representar atletas que se envolvem em modalidades de/para homens, parece refletir uma certa necessidade de investir no reforço de uma dada feminilidade, ligando a elas atributos tais como delicadeza, graça e beleza. (JAEGER, 2007). Nesse caso, a maternidade confere uma certa segurança, ao indicar que atletas continuam a 
serem mulheres, mesmo jogando futebol pois, nesse contexto, o fato de ser mãe indica sua permanência em uma representação normatizada de feminilidade. Afinal, é "natural" que a mulher seja mãe, mesmo, a atleta.

Sobre a paternidade pouca referência se faz. Ao perscrutarmos o material empírico, identificamos duas reportagens que fizeram menção aos filhos de atletas homens: "Cheguei a pensar em meu filho em dois momentos nesta luta. Ele é uma alegria enorme. Quando penso nele, fico muito emocionado', afirmou o atleta"8. A outra apresenta somente uma frase que faz menção ao filho - que nasceu quando o boxeador já estava em Pequim - para, na sua continuidade, fazer uma longa descrição técnica da luta9. Sem fotos e em poucas linhas, a paternidade foi mencionada apenas nestas duas reportagens, e é representada de modo muito diferente da maternidade: para eles não existe a preocupação de ser atleta e pai ao mesmo tempo, e a paternidade não é um "destino", mas algo que talvez possa Ihes complementar.

Para além da maternidade, outro atributo relacionado a uma representação normatizada de feminilidade foi reincidentemente exibida pelo site: a beleza. $\mathrm{Na}$ reportagem "Atletas olímpicas tiram roupa e viram sensação na Alemanha", podemos ler o seguinte texto: "No entanto, as garotas roubaram a cena não por terem ganho alguma medalha nos Jogos de Pequim, mas sim por terem ficado sem roupa em uma edição da Playboy" 10 . Acompanha a reportagem uma imagem que exibe a judoca Romy Tarangui fotografada com vestimenta apropriada à modalidade que pratica. $O$ interessante é perceber que, conforme a legenda esclarece, esse tipo de uniforme não permite que a atleta exponha seu corpo. Ao analisarmos essa e outras reportagens, além das imagens que as acompanham, destacamos as distinções que se fazem em algumas modalidades esportivas com relação ao uniforme e à exibição do corpo. Em Pequim visualizamos roupas coladas ao corpo em esportes como o atletismo, a natação, o voleibol e o basquete. No entanto, nas lutas essa não parece ser uma prática recorrente, razão pela qual, para a atleta mostrar sua beleza, fez-se necessário despir o quimono. Neste caso, para que o corpo feminino possa ser revelado, suprime-se aquilo que the oculta.

Já na reportagem "Jogadoras de vôlei que roubam a cenal'", o que se vê é exatamente o contrário. A foto que ilustra a matéria exibe dois times de vôlei na

8. Disponível em http://esportes.terra.com.br/pequim2008/interna/0,,Ol309|875-El I 0378,00.html Acesso em 08 set.2008.

9. Disponível em http://esportes.terra.com.br/pequim2008/interna/0,,O13069|35-El I 0378,00.html Acesso em 08 set.2008.

10. Disponível em http://esportes.terra.com.br/pequim2008/galerias/0,,Ol7 I758-Ell 0378,00.html Acesso em 08 set. 2008.

II. Disponível em http://esportes.terra.com.br/pequim2008/galerias/0,,Ol7/918-Ell 0378,00.html Acesso em 07 set. 2008. 
quadra, na qual todas as atletas estão de costas, usando uniformes colados a seus corpos, dando a ver corpos desejáveis mesmo durante sua performance esportiva. A foto é acompanhada da seguinte legenda: "Uniforme de italianas destaca a forma das atletas". Ou seja, mesmo que essa questão tenha passado despercebida, o Site Terra produz esse olhar sobre algumas atletas de algumas modalidades. No caso do futebol feminino, por exemplo, não evidenciamos qualquer menção sobre os uniformes ou ainda, sobre o corpo e a beleza das atletas.

Essa ausência revela a representação de que a beleza é um atributo feminino, e não de mulheres, pois, em algumas modalidades esportivas, tais como o fisiculturismo, o futebol e as lutas, mesmo que as atletas sejam belas, pouco se diz sobre sua beleza e feminilidade. São os detalhes técnicos que ganham visibilidade, conforme evidenciou o site em quase todas as reportagens que mencionavam tais modalidades.

Esse modo de dizer, ou melhor, de silenciar sobre a possível beleza de determinados corpos de mulheres, em especial daqueles que ostentam músculos potencializados, indica o quanto é frágil a naturalização do que sejam os atributos femininos. Em outras palavras, são silenciados porque rompem com as noções de fragilidade, delicadeza e beleza representadas naquilo que social e culturalmente se construiu como atributos próprios das mulheres. A aparência musculosa, além de romper com as representações historicamente produzidas e socialmente partilhadas do feminino, ainda produz novas representações, embaralhando e confundindo antigas e novas referências acerca dos corpos das mulheres (JAEGER, 2009).

Ainda sobre as distinções de gênero, merece destaque a ênfase atribuída pelo site a três "superatletas": dois homens e uma mulher. Vejamos:

Eles são estrelas e praticamente imbatíveis. Entre os 11.990 esportistas que disputam a Olimpíada, três destoam. São superatletas. Para eles a vitória é uma certeza. [...] Ainda faltavam poucos metros para a chegada quando Usain Bolt já sabia que era o campeão [...] Poucos metros dali, poucas horas antes, lá estava outro monstro fazendo história: Michael Phelps. [...] Também tem olhos azuis, corpo escultural, simpatia rara. Pois é. É o diferencial dentro do diferencial. Além de talento ímpar, a russa (Yelena Isinbayeva) tem mais. É bela. (SUPERATLETAS ENTRAM EM AÇÃO JUNTOS E MOSTRAM ABISMO, 2008)

Dois "monstros" e uma "bela" são os superatletas anunciados pelo site. Eles: Usain Bolt, jamaicano, considerado o homem mais rápido do mundo, e Michael Phelps, nadador norte-americano que somou oito medalhas de ouro nos Jogos. Ela: Yelena Isinbayeva, russa, campeã do salto com vara. A designação ligada aos homens é "monstros", que soa como um elogio aos atletas. Ao serem elencados como melhores, são destacados os seus atributos físicos, responsáveis por suas 
conquistas no esporte. Ela, além de campeã, é bela: tem olhos azuis, um corpo escultural, ao contrário de ser uma "monstra". Em momento algum, nesta ou em qualquer outra reportagem disponibilizada durante os Jogos, existe a expressão "monstra", ou ainda, "fera", para uma atleta mulher. No entanto, graça, simpatia, harmonia e beleza são as palavras que comumente figuram em reportagens que destacam as atletas.

A série de fotos que acompanha a reportagem nomeada "Superatletas" reforça as representações de masculinidades e feminilidades presentes no texto. Sob o título "Superatletas entram em ação em Pequim", são exibidas quatro fotos de cada um dos três fenômenos. As legendas para o nadador e o velocista são técnicas: "O americano Michael Phelps mais uma vez marcou a história da natação na final dos I 00 borboleta"; "O fenômeno (Usain Bolt) superou seu próprio recorde mundial por três centésimos". As fotos mostram os superatletas homens executando gestos técnicos de sua modalidade específica. A imagem da superatleta mulher é a única na qual a atleta não aparece realizando gestos próprios de sua modalidade:

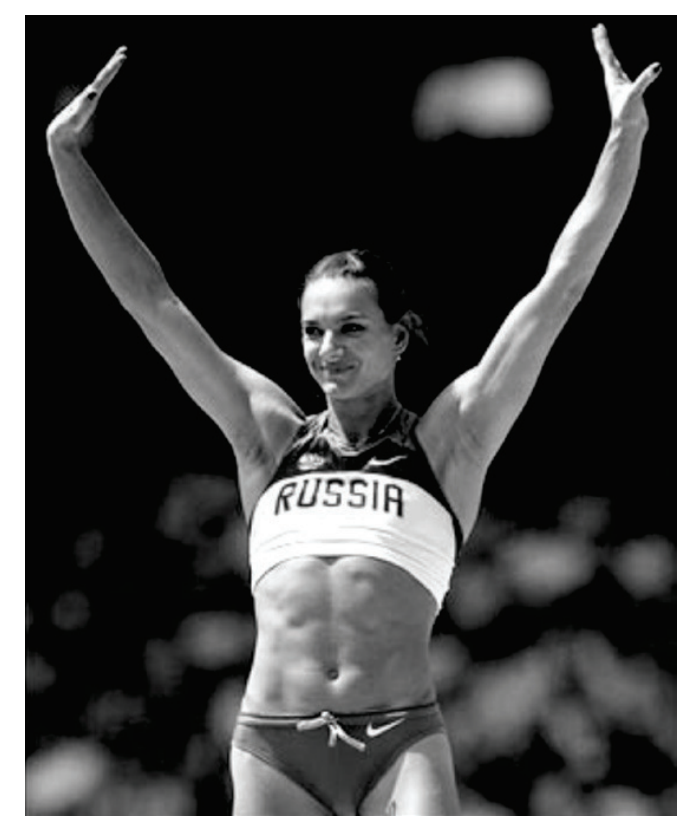

Figura 2. Superatletas entram em ação em Pequim ( 16 de Agosto de 2008).

Fonte: http://esportes.terra.com.br/pequim2008/galerias/0,,Ol72045-El I 0378,00.html. Acesso em: 06 out. 2008.

Yelena Isinbayeva aparece de frente, em posição estática, com os dois braços ao alto, fazendo uma saudação ao público. Veste um pequeno calção e um top que permite enxergar seu corpo minuciosamente esculpido pelo intenso trabalho muscular. Diz a legenda: "Além de talento ímpar, Isinbayeva exibe toda a sua beleza com um corpo escultural". Aqui, ser bela aparece como uma possibilidade da atleta ser exibida, mesmo que a beleza não seja um atributo relacionado ao seu bom 
desempenho esportivo. A beleza é dita e fotografada de maneiras diferentes ao longo dos Jogos de Pequim, constituindo-se como um modo pelo qual o site Terra evidenciou distinções de gênero conferidas aos atletas homens e às atletas mulheres.

\section{MUSOS E MUSAS: A BELEZA "ROUBA A CENA"}

Em uma primeira análise do material empírico, parecia que interessava ao site somente a beleza feminina, a qual, de fato, foi largamente anunciada. No entanto, percebemos que alguns homens também foram representados como belos, o que nos leva a pensar, tal como Luisa Alonso, que o esporte é observado como um local de construção de corpos desejáveis. Na suas palavras:

O campo dos esportes não ficou imune aos novos modelos de imagens corporais elaborados pela transformação cultural. Corpos de atletas que eram vistos como antítese da feminilidade são, atualmente, modelos de beleza perseguidos por todas. A prova mais evidente foi o sucesso do calendário publicado quando dos Jogos Olímpicos de Sidney/ Austrália em 2000. Homens e mulheres atletas nus resplandecendo em corpos que sugeriam sensualidade, mas escondiam o gênero em um jogo de formas e luzes que esmaeceram volumes e contornos sinalizadores do masculino e do feminino. Atualmente, no mundo dos esportes os ideais de beleza são mais claramente assumidos e ainda que um corpo bonito por si só não garanta bons resultados e desempenhos extraordinários eles recebem da mídia atenção redobrada, como são as musas do vôlei brasileiro e algumas tenistas internacionais. Ao lado do reconhecimento da beleza do corpo em si, a vaidade é assumida por homens e mulheres (ALONSO, 2004, p. 96).

A valorização da beleza das/dos atletas se fez bastante visível em duas seções criadas pelo Terra, nas quais veiculava apenas imagens e suas legendas, e que foram intituladas como "Confira uma seleção especial de musas" e "Conheça os musos dos Jogos de Pequim". Se, por um lado, estas seções indicavam um tratamento semelhante para eles e para elas, por outro, tal promessa não vingou.

Após uma análise detalhada de cada seção, foi possível perceber que as semeIhanças entre as duas se encerram no próprio título. "Veja fotos das belas que despertam desejos dos fãs" e, em contraponto, "Veja uma seleção dos gatos que valem ouro". Ressaltamos que a expressão "musas" é rotineiramente usada às mulheres pelo site, já a expressão "musos" somente aparece nessa seção, sendo que em nenhuma outra reportagem, seção de fotos ou em alguma legenda específica se atribui essa expressão a um homem. $O$ tratamento dado à beleza de homens e mulheres atletas, ou ainda, aos musos e musas, só oferece paridade aos olhos mais desavisados.

A seção de "belas que despertam desejos nos fãs" possui 25 fotos nas quais as atletas aparecem em ação, porém há alguns escapes como veremos a seguir. 
As legendas dessas 25 imagens usam expressões como: "belas", "sorridente", "musa", "ex-miss", "sensuais", "curvas", "beldade", entre outras. A seção de "gatos que valem ouro" é composta por I 8 fotos, e exibe os atletas executando algum gesto esportivo próprio das modalidades que praticam, ou sendo fotografados no momento em que estão recebendo as medalhas conquistadas. "Gato", "sorriso", "galã", "estrelas", "belos", bem-afeiçoados, "homem com cara de másculo" são as palavras que figuram nas legendas dessas imagens.

Interessa perceber que algumas "musas" são atletas que só foram exibidas por sua beleza, e não por apresentarem uma boa ou má performance olímpica. Exemplo dessa afirmação é a exibição de uma atleta identificada como "ex-miss Paraguai" que, na seção "Musas", figura em três das imagens disponibilizadas. Sua fotografia é exibida, também, na seção: "Brasileira é eliminada no lançamento de dardo"'2, na qual são exibidas 13 fotos, e apenas três são da brasileira. Oito das fotos veiculadas retratam a ex-miss, com legendas de cunho técnico, como, por exemplo: "Leryn Franco, do Paraguai, se prepara, mas termina a eliminatória na $25^{a}$ colocação". Nenhuma das imagens da atleta paraguaia a retrata em ação, todas são fotos da ex-miss em posições estáticas que ressaltam seus atributos estéticos.

Os musos eleitos e fotografados pelo site são todos atletas que obtiveram bons resultados nos Jogos Olímpicos. Sua beleza é atributo necessário para serem classificados como "musos". Porém, sempre ligado a ela, aparecem argumentos técnicos das suas modalidades, fato evidenciado nas legendas das fotos - o que não acontece com as musas. Para as mulheres a lógica soa inversa: para ser musa precisam ser belas, sensuais. Se, além disso, tiveram alguma conquista esportiva, então esse fato é mencionado, pois seu desempenho não é condição para estarem escaladas nesse time.

Vale ressaltar, ainda, o quanto os corpos de homens e mulheres são fotografados de maneira diferente. Se, para os homens, as lentes tendem a enquadrar o tórax, para os corpos femininos as lentes parecem não ter essa pretensão, sendo alvo costumeiro o "bumbum"|'. Sobre esse modo de dar a ver corpos masculinos e femininos, chama a atenção duas imagens, ambas relacionadas ao vôlei de praia, e aparecem acompanhando as reportagens intituladas "Walsh/May leva ouro no vôlei de praia" e "Ricardo/Emanuel mantém 100\%".

12. Disponível em http://esportes.terra.com.br/pequim2008/galerias/0,,Ol72699-El l0378,00.html Acesso em 06 de out. 2008.

13. Usamos essa expressão porque é a mais usada pelo site Terra, tanto nos textos quanto nas legendas que identificam as fotografias. 


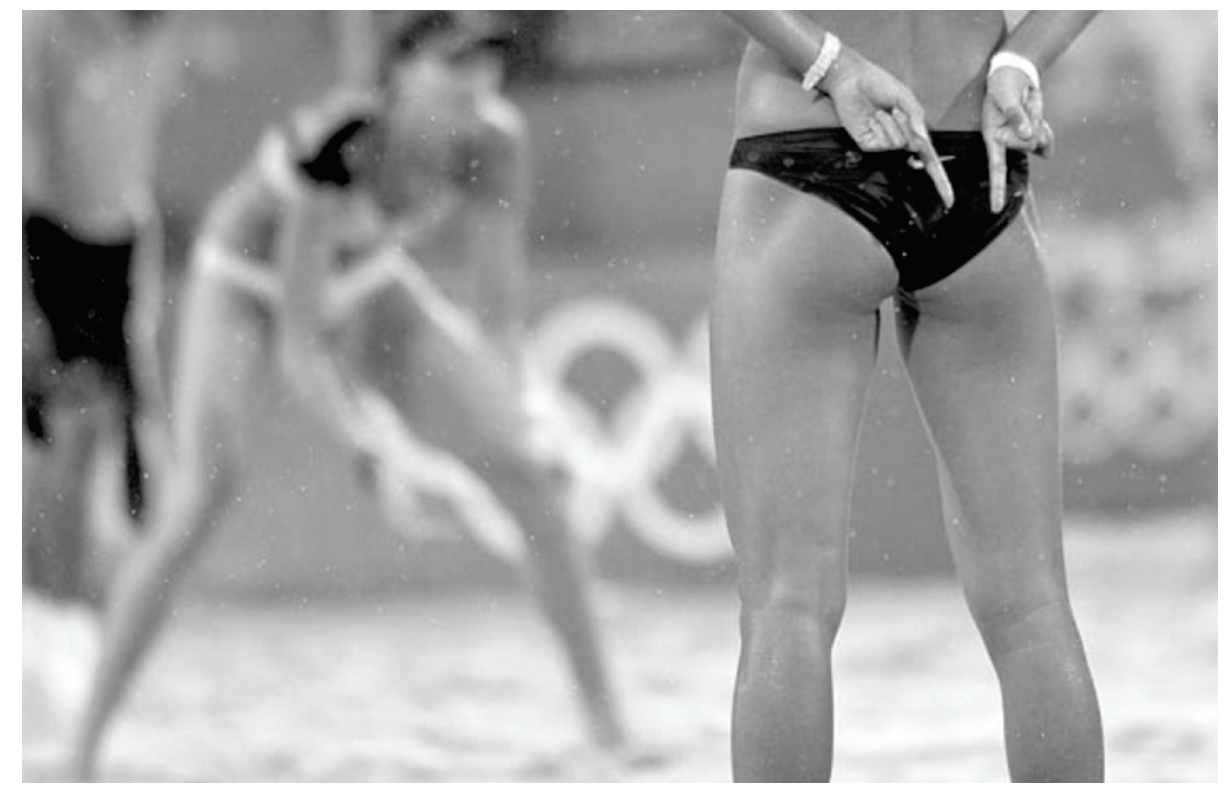

Figura 3. Walsh/May leva ouro no vôlei de praia (2I de Agosto de 2008).

Fonte: http://esportes.terra.com.br/pequim2008/galerias/0,,Ol72583-Ell 0378,00.html. Acesso em: 07 set. 2008.

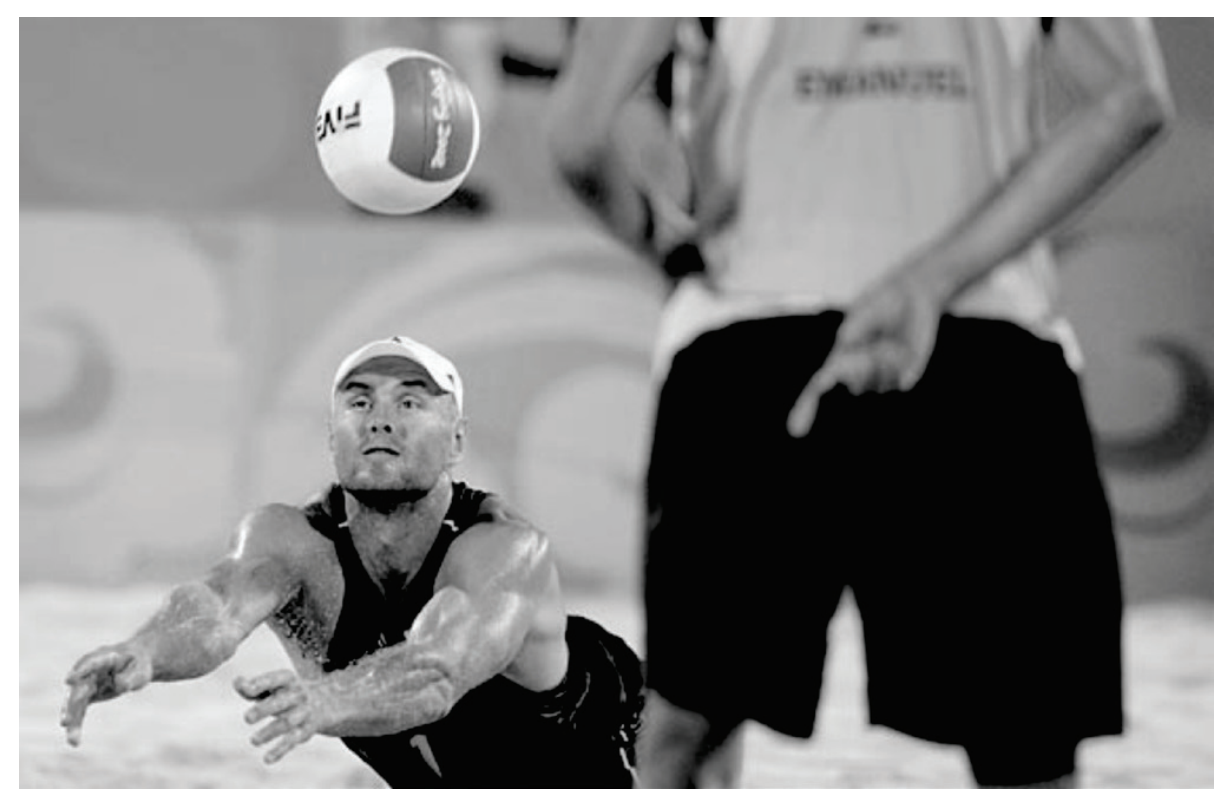

Figura 4. Ricardo/Emanuel mantém 100\% (13 de Agosto de 2008).

Fonte: http://esportes.terra.com.br/pequim2008/galerias/0,,Ol7/560-El I0378,00.html . Acesso em: II out. 2008.

Nelas há uma construção imagética plena de significados no que respeita as representações de gênero, e isso pode ser identificado pelo diferente foco que é conferido a determinada parte do corpo dos atletas homens e das atletas mulheres. $\mathrm{Na}$ foto das atletas, a centralidade e o foco da imagem estão na atleta que aparece de costas e, conforme a legenda, aponta jogada para sua dupla: "Chinesa indica qual será a jogada para sua parceira." A atleta que está ao fundo, mesmo que de frente para a câmara e em posição de jogo, aparece "borrada", em segundo plano 
de visibilidade. Na imagem do vôlei masculino, o destaque, tanto na imagem quanto na legenda, é dado ao jogador que está em ação: "Andrew Schacht se estica para salvar a bola". Ele aparece ao fundo da imagem e isso não é motivo para o foco desviar dele. Quem aparece borrado é o atleta que está de costas, pela metade, em posição estática, mesma posição que para as mulheres foi evidenciada, para os homens foi silenciada.

Este jogo generificado e generificador pode ser observado no material empírico que sustenta essa pesquisa. Nesse sentido, evidenciamos que o site exerceu uma pedagogia pautada pelo reforço às feminilidades e masculinidades normatizadas, conferindo-Ihes visibilidades e positividades.

\section{CONSIDERAÇÕES FINAIS}

Mais do que corpos em movimento, a cobertura do site Terra sobre os Jogos Olímpicos de Pequim conferiu destaque à produção e reprodução de uma imagem positivada de "ser atleta", independente da sua identidade de gênero. Essa percepção indica o quanto o esporte de alto rendimento demanda corpos que ultrapassem limites, quebrem recordes e superem-se a cada instante de competição, esforços esses vistos como edificantes, sejam eles masculinos ou femininos. Essa afirmação, ainda que percebida nas reportagens e imagens veiculadas pelo site, de modo algum minimiza a existência de distinção entre os modos de dizer e exibir as performances de homens e mulheres.

Com relação às representações de masculinidades e feminilidades, o que identificamos em quase todo o material empírico, são aquelas que apontamos como normatizadas $^{14}$, apesar de, em alguns momentos, percebermos certos escapes, notadamente no tocante às atletas mulheres. Mesmo com a ênfase na maternidade e na beleza, o material empírico evidenciou que nem todas as atletas que investem em uma carreira esportiva são, ou desejam ser, belas, maternais e femininas (GOELLNER, 2003). Inclusive porque, em algumas modalidades, pela suas exigências físicas, táticas e técnicas, é necessária a construção de corpos que se afastam dessas representações, a exemplo do halterofilismo e de algumas lutas.

14. Se o gênero é entendido para além de uma categoria analítica, mas também como um marcador que integra a identidades dos sujeitos, acreditamos que a construção da identidade de gênero é normatizada por vários discursos, tais como médicos, religiosos, jurídicos, pedagógicos, entre outros. No entanto, há representações de gênero que escapam da norma, rompem com sua lógica e, portanto, a desconstroem. No caso dos esportes, poderíamos pensar que os corpos moldados pela potencialização muscular das fisiculturistas rompem com uma visão normatizada de feminilidade. São femininas, mas de outro modo. 
Nesse sentido, podemos identificar que o site Terra fez circular distintas representações de atletas e de gênero, grosso modo, relacionados às especificidades de cada modalidade esportiva, visibilizando diferentes corpos de mulheres e homens, atribuindo-lhes distintos enfoques. Se, por um lado, em uma seção de fotos somente a beleza da ex-miss paraguaia é valorizada, por outro, a judoca Ketleyn Quadros é lembrada por sua medalha olímpica inédita para o Brasil, cuja reportagem apresenta várias fotos da atleta em situação de luta. Ambas são mulheres e, em momento algum, se suspeita disso; a diferença que existe é quanto a anunciar as atletas de maneira distintas: uma por ser bela, outra por ser boa atleta.

Como foi possível perceber, o site Terra é um espaço generificado e generificador, que produz e reproduz relações hierarquizadas entre os gêneros. Grande parte dos discursos que nele circularam durante os Jogos Olímpicos de Pequim indicam um jogo de poder, através do qual as representações normatizadas de masculinidade e feminilidade mostraram-se visíveis, enquanto outras (aquelas que da norma se afastam) ficaram nas zonas de sombra. Nesse sentido, podemos afirmar que o site Terra "entrou no jogo", conferindo pouco movimento aos diferentes modos de ser atleta masculino e feminino.

"Gender Game" in Beinjing 2008: representation of femininities and masculinities (re)produced by Terra Website

ABSTRACT: Based on the post-structuralism perspective, more specifically, on the theoretical field of Gender Studies and Cultural Studies, the purpose of this article is to analyse the gender representations that were produced and reproduced by Terra website about athletes that participated in the Beijing Olympic Games. All text and images published in the sections "Last News" and "Photos" during the seventeen days of the competition were collected. The empirical sources consisted of sports news and images and was analysed using the Foucalt's analyses of discourse. Based on the analysis, it was possible to realize that Terra website has shown different masculinities and femininities which generated a "gender game" in which different ways of being an athlete were represented.

KEYWORDS: Cultural Studies; media; gender; Olympic Games.

"Juegos de Género" en Pequin 2008: representaciones de feminidades y masculinidades (re)producidas por el Site Terra

RESUMEN: Fundamentada en la perspectiva pos-estructuralista, más especificamente en los Estudios de Género y en los Estudios Culturales, este artículo tiene como objetivo analizar las representaciones de género producidas y reproducidas por el site Terra sobre los atletas participantes de los Juegos Olímpicos de Pequin. Para tanto fueron colectados todos los textos e imagenes publicados en la sección "Últimas Noticias" y "Fotos" durante los diecisiete días de competición. El material empírico constó de reportajes e imagenes que fueran 
metodologicamente tratados con la análisis de discurso de inspiración foucaultiana. De ese análisis fue posible percibir que el Site Terra exhibió diferentes masculinidades y feminidades, posibilitando la emergencia de un "juego de género", en el cual diferentes modos de ser atleta fueron representados.

PALABRAS CLAVE: Estudios culturales; medios de comunicación; género; Juegos Olímpico.

\section{REFERÊNCIAS}

AJA, T. G. Spain. In: GUTTEMANN, A.; PFISTER, G.; CHRISTENSEN, K. (Ed.). International encyclopedia of women and sports. New York: Mcmillan, 2002. p. I091-1093. v. 3.

ALONSO, L. K. Esporte, imagem corporal e exploração da mídia. In: FÓRUM DE DEBATES SOBRE MULHER \& ESPORTE, MITOS E VERDADES, 3., São Paulo, 2004. Anais... São Paulo: Universidade de São Paulo, 2004, p. 93-97.

BIRRELL, S.; THEBERGE, N. Ideological control of women in sport and feminist resistance and transformation for sport. In: COSTA, M.; GUTHRIE, S. R. (Ed.). Women and sport: interdisciplinary perspectives. Champaign: Human Kinetics, 1994. p. 323-376.

CRUZ, I.; SILVA, P.; GOMES, P. B. Deusas e guerreiras dos jogos olímpicos. Lisboa: Comissão para a Igualdade e para os Direitos das Mulheres, 2006.

FISCHER, R. M. B. Televisão \& educação: fruir e pensar a TV. 2. ed. Belo Horizonte: Autêntica, 2003.

FOUCAULT, M. A arqueologia do saber. 6. ed. Rio de Janeiro: Forense Universitária, 2005 Microfísica do poder. Rio de Janeiro: Edições Graal, 2004.

GIROUX, H.; MCLAREN, P. L. Por uma pedagogia crítica da representação. In: SILVA, T. T.; MOREIRA, A. F. (Org.). Territórios contestados: o currículo e os novos mapas políticos e culturais. Petrópolis: Vozes, 1995.

GOELLNER, S. V. Bela, maternal e feminina: imagens da mulher na Revista Educação Physica. ljuí: Ed. da Unijuí, 2003.

Mulheres, memórias e histórias: reflexões sobre o fazer historiográfico. In: 2007. .; JAEGER A. A. (Org.). Garimpando memórias. Porto Alegre: Ed. da UFRGS,

et al. Pesquisa qualitativa na Educação Física Brasileira: marco teórico e modos de usar. Revista da Educação Física, Maringá, v. 21, p. 381-410, 2010.

GREGOLIN, M. R. Análise do discurso e mídia: a (re)produção de identidades. Comunicação, Mídia e Consumo, São Paulo, v. 4, n. I I, p. I I-25, nov. 2007.

IÑIGUEZ, L. Manual de análise do discurso em ciências sociais. Petrópolis: Vozes, 2004. 
JAEGER, A. A. Mulheres atletas da potencialização muscular e a construção de arquiteturas corporais no fisiculturismo. 2009. Tese (Doutorado) - Escola de Educação Física, Universidade Federal do Rio Grande do Sul, Porto Alegre, 2009.

Quando o músculo entra em cena: fragmentos históricos da potencialização muscular feminina. In: GOELLNER, S. V.; JAEGER A. A. (Org.). Garimpando memórias: esporte, lazer e dança. Porto Alegre: Ed. da UFRGS, 2007. p. I33- 148.

JOGOS DE PEQUIM TEM RECORDE DE AUDIÊNCIA, INTERNET É DESTAQUE. Disponível em: http://esportes.terra.com.br/pequim2008/interna/0,,Ol3 I I 53 I 7-El I 0378.html Acesso em: 21 ago. 2008

HALL, S. Identidade cultural na pós-modernidade. Rio de Janeiro: DP\&A, 1997.

LIOTARD, P.; TERRET, T. Excellence féminine et masculinité hégémonique. Paris: L'Harmattan, 2005.

LOURO, G. L. Um corpo estranho: ensaios sobre sexualidade e teoria queer. Belo Horizonte: Autêntica, 2004.

(Org.). Gênero, sexualidade e educação. Rio de Janeiro: Vozes, 1997.

MEYER, D. E. E. Teorias e políticas de gênero: fragmentos históricos e desafios atuais. Revista Brasileira de Enfermagem, Brasília, jan./fev. 2004.

Gênero e saúde: indagações a partir do pós-estruturalismo e dos estudos culturais. Revista de Ciências da Saúde, Florianópolis, v. 17, n. I, p. 13-32, jan./jun. 1998.

"MINHA FILHA QUERIA PRATA", BRINCA MAURREN. Disponível em: http://esportes. terra.com.br/pequim2008/interna/0,,OI3 I25 I33-El 0378,00.html Acesso em: 05 set. 2008

MOREIRA, L. E.; NARDI, H. C. Mãe é tudo igual? enunciados produzindo o(s) modo(s) de ser mãe. In: SEMINÁRIO INTERNACIONAL FAZENDO GÊNERO, 8., Santa Catarina, 2008. Anais... Florianópolis: UFSC, 2008.

MOURÃO, L. Representação social da mulher brasileira nas atividades físico-desportivas: da segregação à democratização. Movimento, Porto Alegre, ano 7, n. 13, p. 5-18, 2000/2.

ORLANDI, E. P. A análise de discurso em suas diferentes tradições intelectuais: o Brasil. In: In: SEMINÁRIO DE ESTUDOS EM ANÁLISE DE DISCURSO, I ., Porto Alegre, 2003. Anais... Porto Alegre: Ed. da UFRGS, 2003. p. I- I8. CD-ROM.

PALACIOS M.; LEMOS, A. (Org.). Janelas do cyberespaço. Porto Alegre: Sulina, 200 I.

PFISTER, G. Germany. In: GUTTEMANN, A.; PFISTER, G.; CHRISTENSEN, K. (Ed.) International encyclopedia of women and sports. New York: Mcmillan, 200 I. v. 3. p. 45I-456.

ROSE, G. Visual methodologies: an introduction to the visual interpretation of visual materials. London: Sage, 2007. 
SCHARAGRODSKY, P. Construyendo masculinidades y feminilidades católicas y moralmente correctas: el caso de la primera Direción General de Educación Física Argentina ( 1936- 1940). In: AISENSTEIN, A.; SCHARAGRODSKY, P. (Ed.). Tras las huellas de la Educación Física escolar argentina: cuerpo, género y pedagogía. Buenos Aires; Prometeo Libros, 2006.

SILVA, T. T. Documentos de identidade: uma introdução às teorias do currículo. 2. ed. Belo Horizonte: Autêntica, 2007.

O currículo como fetiche: a poética e a política do texto cultural. Belo Horizonte: Autêntica, 2001 .

SCOTT, J. Gênero: uma categoria útil de análise histórica. Educação \& Realidade, Porto Alegre, v. 20, n. 2, p. 7I-99, jul./dez. 1995.

SUPERATLETAS ENTRAM EM AÇÃO JUNTOS E MOSTRAM ABISMO. Disponível em: $<$ http//esportes.terra.com.br/pequim2008/interna/0,,OI3 I 02024-El I 0378,00.html. Acesso em: 08 set. 2008.

SUPERMÃES DEIXAM SUA MARCA EM PEQUIM. Disponível em: http://esportes.terra. com.br/pequim2008/interna/0,,OI3 I22774-El I0378,00.html Acesso em: 05 set. 2008.

WHITE, A. Women and sport in UK, In: HARTMANN-TEWS, I.; PFISTER, G. (Ed.). Sport and women: social issues in international perspective. London: Routeledge, 2003. 35-42.

Recebido: 31 out. 2010 Aprovado: 02 mai. 201 I

Endereço para correspondência: Johanna Coelho von Mühlen ESEF/UFRGS - CEME Rua Felizardo, 750 Porto Alegre - RS - BRASIL CEP: $90690-200$ 